\title{
Size variation of six species of oxudercine gobies along the intertidal zone in a Malayan coastal swamp
}

\author{
G. Polgar ${ }^{1, *}$, V. Bartolino ${ }^{2}$ \\ ${ }^{1}$ Institute of Biological Sciences, Faculty of Science, University of Malaya, 50603 Kuala Lumpur, Malaysia \\ ${ }^{2}$ Institute of Marine Research, Swedish Board of Fisheries, Lysekil, Sweden
}

\begin{abstract}
Reduction in size from sea to land is a common trend of many fish species and communities, at both the intraspecific and interspecific level. Within the intertidal zone, similar trends have been described at the intraspecific level in several transient and resident fish species. Oxudercines are a group of intertidal gobies (Gobiidae: Oxudercinae) including several species, which exhibit extreme adaptations to an amphibious lifestyle. Ecomorphological and ecophysiological considerations suggest that size reduction in this group may have facilitated the adaptation to semi-terrestrial conditions. To test this hypothesis, the spatial ecology and the presence of an intra- and interspecific size gradient was investigated in an oxudercine community of a Malayan intertidal ecosystem (6 species included in 3 genera). A random stratified sampling design was adopted, and ANOVA and cluster analysis performed to describe this variation. Multivariate analyses of the quantity of environmental water were also conducted to investigate the correspondence between size and habitat terrestriality. Larger species were found in more aquatic conditions at lower topographical levels along the vertical intertidal gradient, supporting the hypothesis of an adaptive value of smaller size in more terrestrial habitats. Intraspecific variation showed more complex patterns, even if in several species smaller individuals were found in more terrestrial conditions.
\end{abstract}

KEY WORDS: Intertidal fishes $\cdot$ Size distribution $\cdot$ Habitat partitioning $\cdot$ Spatial ecology $\cdot$ Tropical $\cdot$ Mudskippers · Amphibious fishes · Water to land eco-evolutionary transition

\section{INTRODUCTION}

Our understanding of intertidal ecological and adaptive processes is mainly based on the study of the distribution of sessile organisms along rocky intertidal gradients (Raffaelli \& Hawkins 1999). On the other hand, the study of the spatial and temporal distribution of mobile species living in soft-bottom intertidal environments had frequently been hampered by harsh operational difficulties (Raffaelli \& Hawkins 1999, Gibson 1999).

The species distribution along the intertidal zone is the result of adaptation to autoecological and synecological factors. As a general rule, for aquatic organisms physical conditions and biotic interactions are more challenging at the upper and lower limits of the inter- tidal zone, respectively, while the opposite is true for terrestrial ones (Raffaelli \& Hawkins 1999). Oxudercine gobies (Teleostei: Gobiidae: Oxudercinae; Hoese 1984, Murdy 1989) are an originally aquatic group including several highly amphibious species (mudskippers), widely distributed in the tropical and subtropical belts and also present in some temperate regions. Adults live as intertidal residents (sensu Gibson 1982) of mudflat and mangrove ecosystems and are also distributed in the lower reaches of rivers (e.g. Khaironizam \& Norma-Rashid 2003). The presence of sympatric oxudercine species being differentially distributed along the whole intertidal gradient offers an excellent case study to investigate the differential effects of physical and biotic factors in this group. 
The quantitative spatial ecology and habitat distribution of oxudercine species are poorly known (Clayton 1993). Several descriptive accounts (Milward 1974, Nursall 1981, Swennen et al. 1995, Takita et al. 1999) and a few exploratory or semi-quantitative studies (Muhammad Ali \& Norma-Rashid 2005, Polgar \& Crosa 2009) reported a differential distribution of sympatric species along the intertidal gradient.

According to the present phylogeny consensus (Murdy 1989), the oxudercine genera included in the tribe Periophthalmini form a monophyletic clade (Fig. S1 in the supplement at www.int-res.com/articles/suppl/m409p 199_supp.pdf). Therefore, this group offers the unique opportunity to make a comparative study of the evolution of semi-terrestriality. In particular, Murdy's morphological cladistic analysis (1989) suggests a sequential cladogenesis of increasingly terrestrial genera; nonetheless, the intrageneric variability in habitat selection according to indirect measures of the quantity of water present in the habitat during low tide (quantity of environmental water; Polgar \& Crosa 2009) suggests that the adaptation to semiterrestrial habitats in oxudercine gobies may have been more complex than previously outlined.

The study of ecomorphological patterns within this group might provide insight into possible adaptive scenarios of the eco-evolutionary transition from water to land. In particular, recent studies suggested that smaller mudskipper species and size classes occur in more terrestrial habitats (Muhammad Ali \& Norma-Rashid 2005). The intertidal zone offers a gradient of environmental conditions, where segregation by size can occur. In intertidal fishes, smaller individuals of the same species are often found at higher intertidal levels (Kyphosidae: Hernández et al. 2002; Gobiesocidae, Cottidae, Blenniidae: Zander et al. 1999). This pattern parallels the well-known size gradient among many pelagic and neritic fishes, whose early life stages make use of shallow coastal habitats (e.g. Gillanders et al. 2003).

Juveniles of intertidal stichaeoid species were found to be less efficiently adapted than adults to evaporative water loss, suggesting that desiccation may prevent smaller fishes from colonising upper intertidal levels (Horn \& Riegle 1981). Larger evaporative losses in smaller individuals would result from higher surface to volume ratios; nonetheless, these would also increase diffusion rates through the integument, improving the efficiency of subaerial cutaneous respiration and excretion (Horn \& Riegle 1981, Evans et al. 1999). Water losses could also be compensated by the easier selection of appropriate conditions at the microhabitat level (Sayer 2005). At the synecological level, the spatial partitioning of different size and age classes amongst different habitat types can decrease niche overlap and increase resource partitioning (Spina 2000), being mediated either by interference competition or predation (e.g. Freeman \& Stouder 1989, Harvey \& Steward 1991).

When different species are compared, the smaller size of intertidal fish species relative to neritic and pelagic ones is a peculiar and widespread trait throughout different biogeographic regions, even in the palaeontological record (Horn 1999, Schultze 1999). Nonetheless, we are unaware of other interspecific comparative studies of size gradients amongst intertidal fishes.

Our working hypothesis is that decrease in body size is a specific adaptation to an amphibious lifestyle, which promoted colonisation of more terrestrial habitats. Six oxudercine gobies from a Malayan intertidal ecosystem (Tanjung Piai, near the tip of mainland Asia; Fig. 1) were our model species: Boleophthalmus bod-

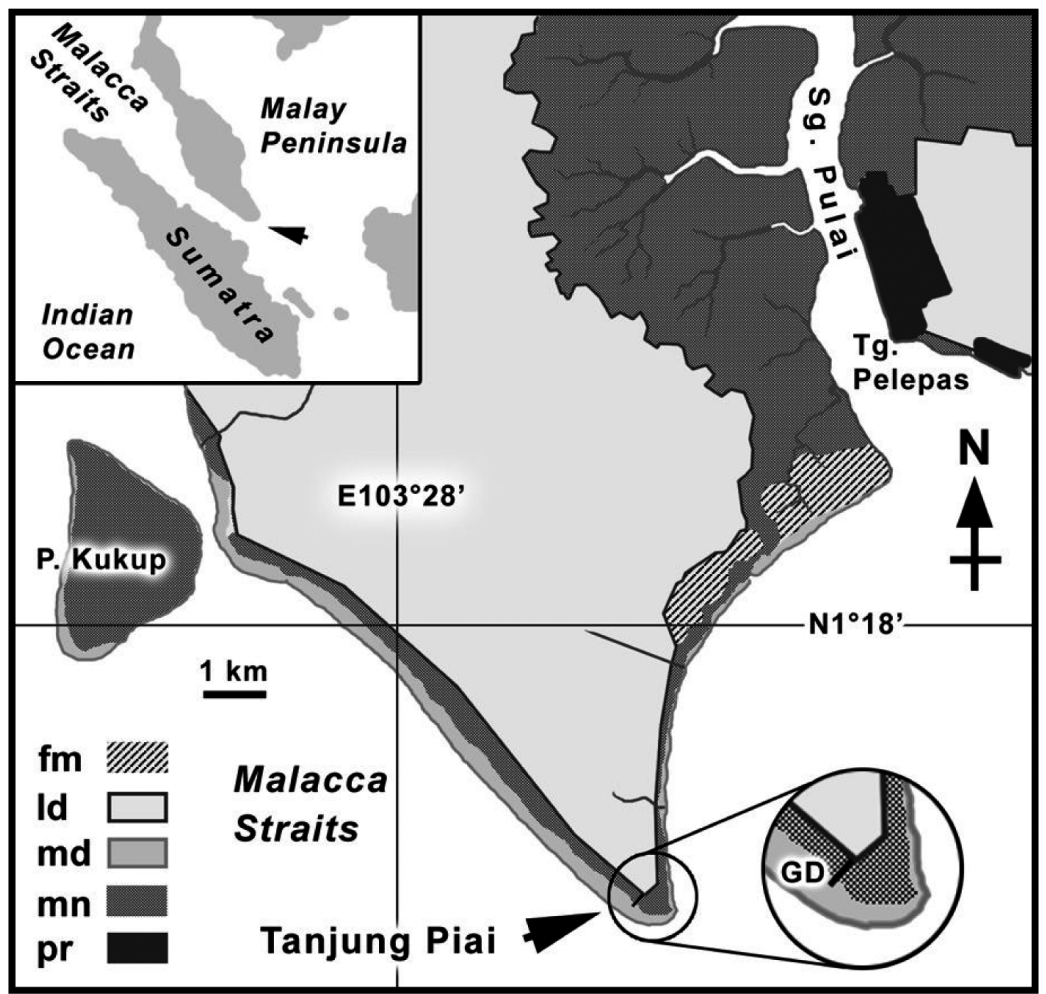

Fig. 1. Study site: Tanjung Piai (Johor, western Peninsular Malaysia). fm: shrimp farms; ld: reclaimed land; md: mudflats (approximate extension at mean low tide); mn: mangrove forests; pr: seaports; GD: sampling grid; P.: Pulau (= island); Sg.: Sungai (= river); Tg.: Tanjung (= cape). The grid was $228 \mathrm{~m}$ long from the visitor complex to the sea (direction: $40^{\circ} \mathrm{N}$ ) 
darti (Pallas, 1770); Boleophthalmus pectinirostris (Linnaeus, 1758); Periophthalmus chrysospilos Bleeker, 1852; Periophthalmus gracilis Eggert, 1935; Periophthalmus variabilis Eggert, 1935; and Oxuderces dentatus Eydoux \& Souleyet, 1848.

The aims of this study were (1) to conduct the first community analysis of oxudercine gobies based on a random stratified sampling design; (2) to measure the spatial variation of oxudercine species along the intertidal zone in terms of relative abundance and size during low tide; (3) to explore possible associations between the observed spatial variation and several continuous and ordinal environmental parameters describing the availability of environmental water (Polgar \& Crosa 2009); (4) to investigate whether synecological interactions can partly explain the distributional and co-occurrence patterns observed, at the spatial scale considered; and (5) to compare spatial distribution and species size patterns with the present phylogeny consensus at the genus level.

\section{MATERIALS AND METHODS}

Study site, fieldwork experimental design and species. Fieldwork was conducted between 7 October and 14 November 2006, along the west coasts of Peninsular
Malaysia (Johor), in the Johor National Park and Ramsar site of Tanjung Piai, near the southernmost tip of mainland Asia (1ํ $16^{\prime} \mathrm{N}, 103^{\circ} 30^{\prime} \mathrm{E}$; Ramakrishna et al. 2001; Fig. 1). The mangrove park of Tanjung Piai includes a narrow fringe forest and a wide open mudflat along the coast (Fig. 2). The coastal areas around Tanjung Piai experienced several erosive and depositional events during the last $15 \mathrm{yr}$ (H. Singh, L. Tokiman, pers. comm.), including the recent formation of the wide mudflat ( 1 to $1.5 \mathrm{~km}$ during low tide: Ramakrishna et al. 2001, L. Tokiman, pers. comm.).

All field measurements on fish habitats and sampling protocols were conducted on exposed substrates, during low tide. Tidal data were obtained from the reference tidal station of Tanjung Piai, Johor, Malaysia (Admiralty EasyTide ${ }^{\complement}$ UK Hydrographic Office). This site is a meso-macrotidal system; during the period of study, the average tidal excursions were of 1.6 and $2.6 \mathrm{~m}$ during neap and spring tides, respectively. Tidal datums were calculated from tide tables over a period of 3.5 mo (between 31 July and 14 November 2006). Prevalent currents alongshore are NW directed and transport fine sediments from the east coast of the cape (Ramakrishna et al. 2001). At a linear distance of about $10 \mathrm{~km}$, the fluvial discharge of Sungai Pulai is reasonably one of the most important sources of suspended sediments for the study site (Fig. 1). Wave action can

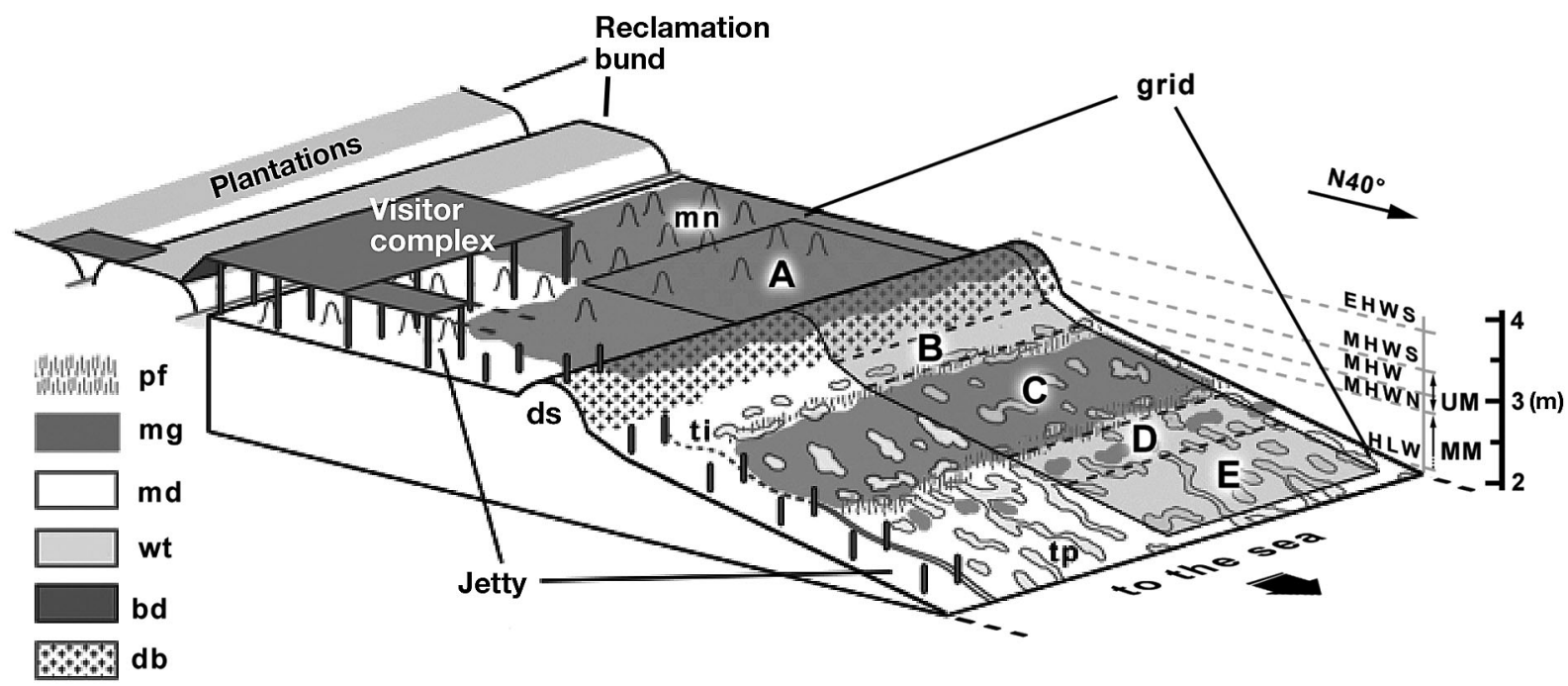

Fig. 2. Block diagram illustrating the position of the sampling grid at Tanjung Piai, Johor, Malaysia. A reclamation bund with a channel regulated by a sluice gate separated the mangrove forest from palm-oil plantations. The grid had its longer side parallel to the jetty $20 \mathrm{~m}$ apart (the right side of the jetty is not visible in figure, for better clarity), and was divided into 5 strata (A to E). A: high Rhizophora and Bruguiera spp. forest; B: small open mudflat in front of an erosive step above MHW (Sasekumar 1974); C: low Avicennia spp. forest, delimitated by the 2 pneumatophore zones (pf); D: sparse trees of Rhizophora mucronata; E: open mudflat; the debris step (ds) was formed by deposited flotsam and vegetal debris (db) and separated the high forest from the low forest: no mudskippers were found here; bd: buildings (visitor complex and jetty); mg: mangrove vegetated area; md: exposed unvegetated mud; wt: water (tide pools, inlets, bund channel); mn: crustacean mud mounds; ti: tidal inlet; tp: tide pools; UM: upper mudflat; MM: middle muflat (UM, MM from Dyer et al. 2000). HLW: highest low water (2.2 m); MHWN: mean high water neap (2.9 m); MHW: mean high water level (3.1 m); MHWS: mean high water spring (3.3 m); EHWS: extreme high water spring $(3.8 \mathrm{~m})$ (Admiralty EasyTide ${ }^{\odot}$ ) Crown copywright and/or database rights. Reproduced by permission of the Controller of Her Majesty's Stationery Office and the UK Hydrographic Office (www.ukho.gov.uk) 
be relatively intense, with maximum significant offshore wave height of $1.75 \mathrm{~m}$ from $\mathrm{W}\left(\mathrm{N}^{\circ} 270\right)$ and SE $\left(\mathrm{N}^{\circ} 120\right)$, and of $2.0 \mathrm{~m}$ from $\mathrm{SSE}\left(\mathrm{N}^{\circ} 150\right.$; synoptic surface meteorological observations, N. H. Mohd Ghazali, pers. comm.). Salinity in the Malacca Straits varies with rainfall, with salinity ranging from 27 to 32 and 2 minima in May and November-December, respectively, during the southern and northern monsoons, respectively (Sasekumar 1980). Within the intertidal zone, salinity fluctuations are determined by rainfall, evaporation and tidal action, becoming more extreme in the high intertidal and supratidal zone (3 to 50; Sasekumar 1974, 1994).

A random stratified sampling design was adopted to quantify the differential habitat distribution of the studied species (Raffaelli \& Hawkins 1999). Contrary to transect designs, this approach allows statistical treatment and between-site comparisons when the same pattern of stratification is observed (Lessios 1996). A georeferenced rectangular grid $(228 \times 36 \mathrm{~m})$ was built along the intertidal zone, with its longer side parallel to the park's jetty, at a distance of $20 \mathrm{~m}$ from it (Figs. 1 \& 2). The grid was divided into $20 \times 4$ nodes, positioned at $12 \mathrm{~m}$ intervals. Preliminary surveys and sampling sessions allowed us to define strata, test the efficacy of sampling techniques, and estimate the number of sampling units.

Five strata were defined (A to E in Fig. 2), with decreasing densities of vegetation coverage from land to sea (Polgar \& Crosa 2009). Stratum A included the higher forest, dominated by Rhizophora and Bruguiera spp. mangroves and characterised by the mud mounds built by the grapsid Episesarma spp. and the anomuran Thalassina anomala. Stratum B was a narrow area 3 to $5 \mathrm{~m}$ wide in front of the erosive step (debris step, Fig. 2); this area was unvegetated and slightly sloped. Stratum C included the lower forest, dominated by Avicennia alba mangroves and delimitated by 2 pneumatophore zones, one in front of Stratum B and the other one by the sea. Stratum D was a belt of sparse and relatively old trees of Rhizophora mucronata (spaced more than $5 \mathrm{~m}$ from each other). Stratum E was the upper portion of the wide unvegetated mudflat.

Sampling units were $4 \times 4 \mathrm{~m}$ quadrats: a trade-off between capture efficiency, operational time, and reduction of variance between units due to microhabitat variability (Holme \& McIntyre 1971). On average, the minimum distance between 2 units was $\sim 10 \mathrm{~m}$, reducing habitat disturbance and non-independence of quadrats (Raffaelli \& Hawkins 1999, Gotelli \& Ellison 2004 ) at the order of magnitude of fish size ( 4 to $20 \mathrm{~cm}$ ). Due to the existence of different types of operational difficulties along the intertidal zone, 2 types of quadrats were used.
Inside densely forested areas (Strata A \& C) and in areas with firmer mud (Stratum B), we used a $4 \times 4 \mathrm{~m}$ stake net $(1.2 \mathrm{~mm}$ mesh size and $60 \mathrm{~cm}$ high; Gibson 1999; Muhammad Ali \& Norma-Rashid 2005). Each selected area was slowly approached by crawling on knees; the net was then slowly unrolled and stakes inserted, gradually surrounding and eventually closing it. Each gap between the net and the substrate was sealed with mud during the process. Then fishes were captured by hand nets. Immediately after capture in Strata A to C, all gobies were transported live to the laboratory, where they were measured ( $\mathrm{TL}$, total length), identified to species level (Murdy 1989, Murdy \& Takita 1999, Takita et al. 1999, Darumas \& Tantichodok 2002, Jaafar et al. 2006, Jaafar \& Larson 2008, Jaafar et al. 2009), and finally released after 1 to $2 \mathrm{~d}$. A few specimens smaller than $2 \mathrm{~cm}$ TL could not be identified to species level and were excluded from the analysis.

On open and soft mudflats (Strata D \& E), mudskippers were much more sensitive to movement, and the fleeing distance of larger individuals was more than $4 \mathrm{~m}$, making stake nets useless. Moreover, several species living in these habitats took shelter into deep territorial burrows (e.g. adult Boleophthalmus spp.), where they rapidly disappeared. On the other hand, the flat landscape and the lack of vegetation considerably facilitated field observations from the distance. Therefore, a visual census was made, always utilising $4 \times 4$ quadrats as sampling units. Specimens larger than about $5 \mathrm{~cm}$ TL were identified and counted in the field (Polgar \& Crosa 2009) by binoculars (Sakura $\left.{ }^{\odot}, 10 \times 42\right)$. Smaller individuals were then counted by approaching the quadrat at 1 to $2 \mathrm{~m}$; the PVC pipes (width $=2.5 \mathrm{~cm}$ ) delimitating the quadrat were used as a visual comparison for length estimates. A comparable efficiency of detection of the 2 sampling methods in the different habitat conditions was assumed (as in Muhammad Ali \& Norma-Rashid 2005).

The sampling effort (number of sampling units) by stratum was allocated proportionally to its area (i.e. the number of its nodes; Table S1 in the supplement at www.int-res.com/articles/suppl/m409p199_supp.pdf). Sampling units were positioned in the immediate proximity of nodes within each stratum; both their selection and the sampling temporal sequence were randomised (Haahr 2006).

Only a few specimens of Periophthalmus argentilineatus Valenciénnes, 1837 (Strata B \& C), Periophthalmodon schlosseri (Pallas, 1770) (Strata A, D and E), and Periophthalmus walailakae Darumas and Tantichodok, 2002 (Stratum C) were captured or observed $(<4 \%$ of the total); therefore, these species were not included in the analyses. 
Spatial and temporal distribution. The whole study was conducted during the relatively dry intermonsoon period, from the end of the southern monsoon to the beginning of the northern monsoon. When it was raining, no sampling was carried out.

To control for the influence of the synodic (Colombini et al. 1995, Ikebe \& Oishi 1997) and daily tidal cycles, Strata B to E were sampled only $\pm 3 \mathrm{~d}$ around spring tides, and $\pm 2 \mathrm{~h}$ around predicted low tide, when these strata were completely exposed. Stratum A was sampled during low neap tides; nonetheless, tides had a minimal effect here, since during observations high waters reached this area only during extreme spring tides, or when the sluice gate of the bund channel was closed with delay (Fig. 2).

Environmental parameters. The method of English et al. (1997; Fig. S2 in the supplement) was used to obtain a linear topographic profile along one side of the grid, from the debris step to the mudflat (Strata B to E in Fig. 2, Fig. S3 in the supplement), correcting for wave action (Mazda et al. 1997; Fig. S2). Within Strata $\mathrm{B}$ to $\mathrm{E}$, topographic levels (LV), tide tables and tidal curves were used to calculate the frequency of emersion of quadrats $(E M)$, i.e. percentage of time that quadrats were exposed over the period of study (Coleman et al. 1970, Sasekumar 1974; Table 1), and their period of emersion before sampling $(\mathrm{HO}$, in decimal hours; Table 1).

Digital drawings in scale were obtained from rectified digital images (Archis v. 2.2 ${ }^{\odot}$ SISCAM; $_{\text {Adobe }}{ }^{\circledR}$
Photoshop ${ }^{\circledR}$ CS2 v. 9.0.2) obtained from several photos of each quadrat taken immediately before sampling. These sketches were used to measure the relative wet area (WA), i.e. the percentage of the quadrat's area covered either by semi-liquid mud (Strata D \& E) or by water (Table 1, Fig. S4 in the supplement).

Four ordinal parameters were also utilised to measure the quantity of environmental water present in the fish habitats during low tide (Table 2): density of vegetation coverage (VC), water bodies (WB), tidal influence (TI), and structural elements (SE). The classification of mangrove forests of different density (VC) followed the work by Sasekumar (1980); denser forests reduce the evaporation rates at ground level (Sarpedonti \& Sasekumar 1996), thereby increasing the quantity of available water. Three levels of increasing VC were observed. WB are hydrogeomorphic and bioturbation structures, which contain water during low tide. WB depend on the energy of the sedimentary environment (tides, currents), weather, and animal burrowing activity. We observed 3 types of WB of decreasing size (Table 2). TI was categorised by taking into account both the topographic profile and tidal datums, classifying each quadrat according to the lowest tidal level that would submerge it. This ordinal parameter is directly associated with $\mathrm{EM}$ and $\mathrm{HO} ; 4$ classes of quadrats were defined (Table 2). SE are dead or live parts of plants, which increase substrate heterogeneity, thus increasing humidity, the amount of capillary water at ground level, and the diversity of micro-

Table 1. Number of specimens per species or stratum, and 2 types of environmental parameters. In square brackets: number of quadrats in which the species occurred versus total number of quadrats; total: absolute and relative (in parentheses) number of sampled specimens by species and by stratum (see Fig. 2 for details). B.: Boleophthalmus; P.: Periophthalmus; O.: Oxuderces. Parameter values are given as mean $\pm \mathrm{SD}$. (HO: time since the last immersion, at the time of measurements; WA: ratio of the area covered by free water or semi-liquid mud to the total area of the quadrat). See Table 2 for details on ordinal parameters

\begin{tabular}{|c|c|c|c|c|c|c|}
\hline & \multicolumn{5}{|c|}{ - Strata } & \multirow{2}{*}{ Total } \\
\hline & A & B & $\mathrm{C}$ & $\mathrm{D}$ & E & \\
\hline \multicolumn{7}{|l|}{ Species } \\
\hline P. gracilis & $22[3 / 10]$ & 0 & $8[3 / 6]$ & 0 & 0 & $30(0.08)$ \\
\hline P. variabilis & $9[5 / 10]$ & 0 & $6[3 / 6]$ & 0 & 0 & $15(0.04)$ \\
\hline P. chrysospilos & 0 & $103[2 / 2]$ & $88[6 / 6]$ & $51[5 / 5]$ & $9[4 / 4]$ & $251(0.71)$ \\
\hline B. boddarti & 0 & 0 & $2[2 / 6]$ & $12[4 / 5]$ & $4[3 / 4]$ & $18(0.05)$ \\
\hline B. pectinirostris & 0 & 0 & 0 & $7[3 / 5]$ & $18[4 / 4]$ & $25(0.07)$ \\
\hline O. dentatus & 0 & 0 & 0 & $9[2 / 5]$ & $7[2 / 4]$ & $16(0.05)$ \\
\hline Total & $31(0.09)$ & $103(0.29)$ & $104(0.29)$ & $79(0.22)$ & $38(0.11)$ & $355(1.00)$ \\
\hline \multicolumn{7}{|l|}{ Continuous parameters } \\
\hline Frequency of emersion (EM, h) & - & $0.8 \pm 0.0$ & $0.8 \pm 0.1$ & $0.5 \pm 0.1$ & $0.4 \pm 0.0$ & \\
\hline Hours of emersion $(\mathrm{HO}, \mathrm{h})$ & - & $4.9 \pm 0.8$ & $5.0 \pm 1.1$ & $3.3 \pm 0.7$ & $2.8 \pm 0.5$ & \\
\hline Topographic level (LV, m) & - & $2.9 \pm 0.0$ & $2.7 \pm 0.1$ & $2.3 \pm 0.2$ & $2.0 \pm 0.0$ & \\
\hline Wet area (WA) & $0.01 \pm 0.02$ & $0.29 \pm 0.00$ & $0.37 \pm 0.11$ & $0.52 \pm 0.24$ & $0.56 \pm 0.14$ & \\
\hline \multicolumn{7}{|l|}{ Ordinal parameters } \\
\hline Vegetation coverage (VC) & $3.0 \pm 0.0$ & $1.0 \pm 0.0$ & $2.0 \pm 0.0$ & $1.0 \pm 0.0$ & $1.0 \pm 0.0$ & \\
\hline Water bodies (WB) & $2.7 \pm 0.5$ & $1.0 \pm 0.0$ & $1.0 \pm 0.0$ & $1.0 \pm 0.0$ & $1.0 \pm 0.0$ & \\
\hline Tidal influence (TI) & $4.0 \pm 0.0$ & $3.0 \pm 0.0$ & $2.2 \pm 0.4$ & $1.8 \pm 0.4$ & $1.0 \pm 0.0$ & \\
\hline Structural elements (SE) & $4.0 \pm 0.0$ & $1.0 \pm 0.0$ & $2.7 \pm 0.5$ & $1.0 \pm 0.0$ & $1.0 \pm 0.0$ & \\
\hline
\end{tabular}


Table 2. Ordinal environmental parameters (modified from Polgar \& Crosa 2009), measured during low tide. Higher values correspond to more terrestrial conditions. HLW: highest low water; MHWN: mean high water neap; MHWS: mean high water spring

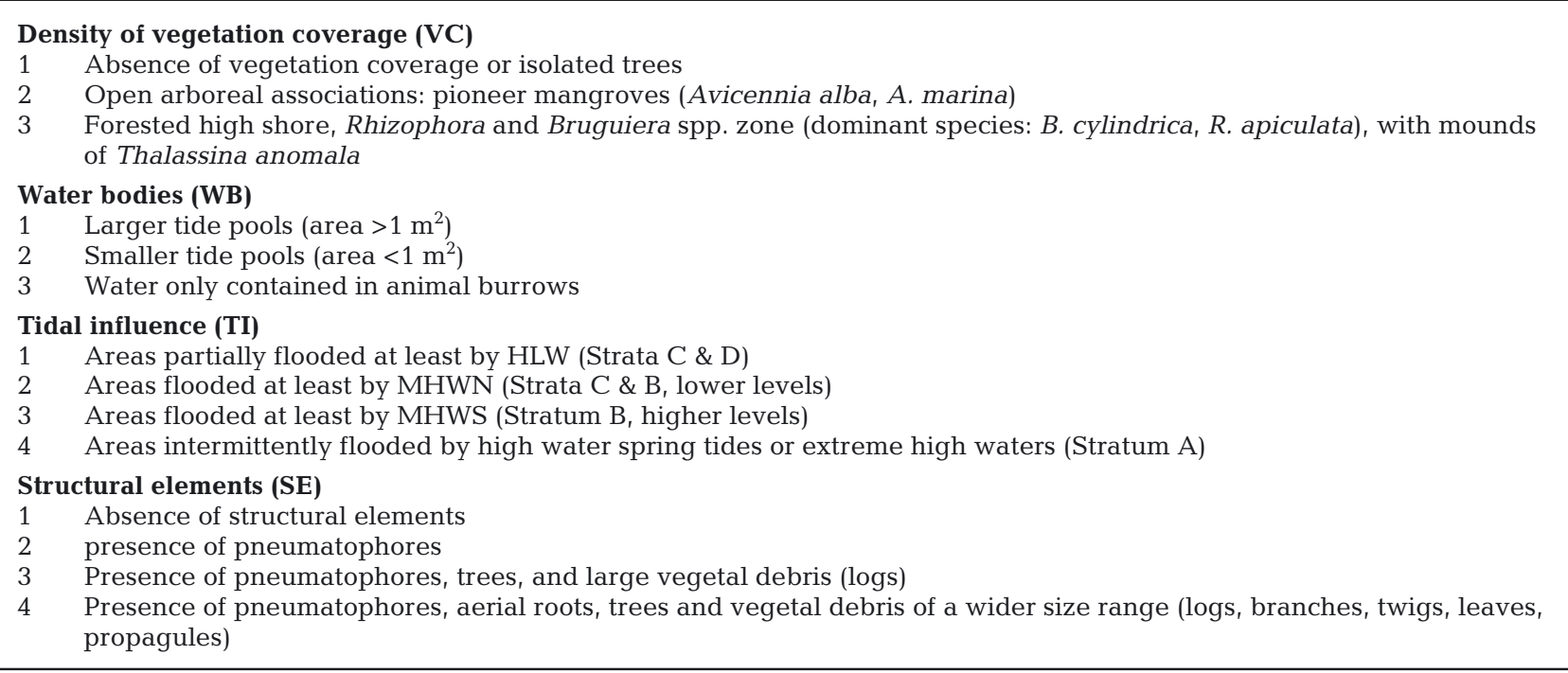

habitat conditions. Four combinations of different types of SE were described, which corresponded to increasing levels of substrate heterogeneity (Table 2).

Statistical analyses. To verify whether the proposed strata corresponded to a gradient of environmental water, they were classified by a cluster analysis made by utilising all measured environmental parameters, and the Gower index, the default measure for mixed similarity/distance measures (ordinal and continuous parameters: PAST $1.93^{\circledR}$; Hammer et al. 2001, Hammer \& Harper 2005).

The abundance matrix was used to test the heterogeneity of species distribution among strata in a contingency table; then one-way ANOVA and post-hoc tests (Tukey's honestly significant difference test) or analogous non-parametric techniques (Kruskal-Wallis rank sum test; Mann-Whitney $U$-test) and standard statistical corrections of $\mathrm{p}$-values for multiple pairwise comparisons (Holm's Bonferroni correction) were used to test the fish size distribution among strata (STATISTICA $7^{\circledR}$, StatSoft). The same approach was used to test the variation of size among and between species. Each species was then tested for differences of size among strata; when significant differences were found, we defined different size classes, using midpoints of mean size in each stratum as cutoff values. To test initial trends, the similarity between species and size classes was assessed with respect to their distribution amongst strata, by cluster analysis of abundance data after transformation as percentages (UPGMA, Bray-Curtis similarity index; Hammer \& Harper 2005; PAST $1.93^{\circledR}$ by Hammer \& Harper 2001).

Multiple correspondence analysis (MCA; XL-STAT 7.5.3 ${ }^{\odot}$, Addinsoft) was conducted to explore both the correspondence between the ordinal parameters of environmental water (SE, TI, VC, WB as observations) and the occurrence of species and size classes (as modalities), and the association between different species and size classes. To do so, we recorded the presence of each species and size class in the conditions described by the variables (Table S2 in the supplement), assuming an equiprobable distribution of fishes among different environmental conditions. MCA is an exploratory technique analogous to principal component analysis (PCA) for categorical and ordinal variables (Jobson 1992). To test the observed associations in the factorial space, we performed an agglomerative hierarchical clustering (AHC; XL-STAT 7.5.3ㅇ, Addinsoft) on the same matrix, adopting the Jaccard similarity index and the strong linkage aggregation method (Johnson \& Wichern 1992).

To visualise how species and size classes were associated with continuous environmental parameters, each individual was plotted in the space defined by 2 normalised parameters, and grouped with other individuals of the same species and size class by $80 \%$ concentration ellipses (PAST 1.93`; Hammer et al. 2001, Hammer \& Harper 2005). Only uncorrelated variables were utilised.

To investigate whether synecological factors (e.g. competition) may also influence species and/or size class distribution in homogeneous environmental conditions, we also tested the presence of non-random patterns of co-occurrence amongst quadrats within each stratum, in a presence-absence matrix (ECOSIM $7.72^{\circledR}$, Kesey-Bear and Acquired Intelligence; Gotelli \& Entsminger 2002). In the null-model simulation (5000 replicates), we set the total number of occur- 
rences of species and size classes in all quadrats to be the same as in the original matrix, and the number of occurrences of each species and size classes to be randomly distributed among sites. In this way, we assumed that within each stratum all quadrats were equiprobable, i.e. they were equally likely to be occupied by different species and size classes (Gotelli \& Entsminger 2002). All degenerate simulation matrices were retained, and 3 co-occurrence indexes were calculated for each stratum (Gotelli \& Entsminger 2002): average number of mutually exclusive outcomes between all possible pairs of species (C-score), number of pairs which never co-occur (number of checkerboards), and number of unique combinations of species and size classes.

\section{RESULTS}

The total sample included 355 specimens (Fig. S5 in the supplement, Table 1). Forests (Strata A \& C) occupied the majority of the study area; the portion occupied by the sparse Rhizophora mucronata trees and the open mudflat (Strata D \& E) was less than half the whole forested area (Fig. 2). At lower topographic levels relative to the grid, thixotropic sediments were more abundant, and the density of the studied species during low tide markedly decreased.

The contingency table (Table 1) showed that the species were significantly not homogeneously distributed (Pearson's Chi-squared test, df $=15, \mathrm{p}<0.0001$ ). The analysis of variance revealed that fish size was significantly different among strata ( $p<0.05$; Fig. 3a \& Table 3a); in particular, fish size in Stratum E was significantly larger than in all other strata, and fish size in Stratum D was significantly larger than in Stratum A. Fish size was also significantly different among species (Fig. 3b, Table 3b): both Boleophthalmus spp. were larger than all other species, and Periophthalmus gracilis was smaller than Periophthalmus variabilis.

Four species exhibited a significant size variation among strata ( $\mathrm{p}<0.05$; Fig. 4), and 2 size classes were defined within each stratum (smaller class: TL $\leq$ midpoint between means; larger class: TL > midpoint between means): Periophthalmus gracilis (midpoint $=$ $4.0 \mathrm{~cm}$, TL in Stratum C > TL in Stratum A), P. variabilis
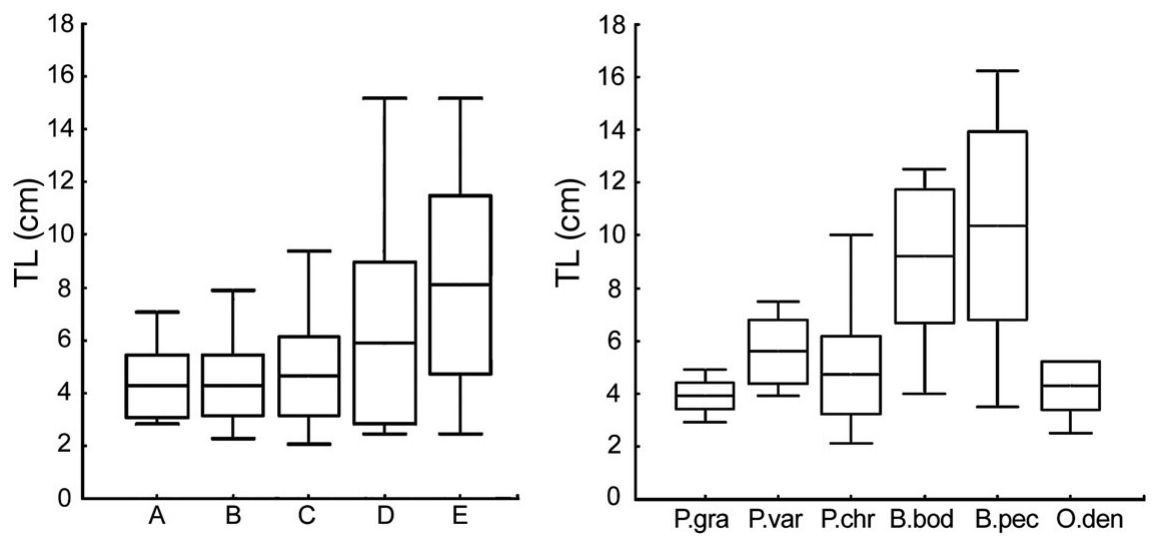

Fig. 3. Fish size (total length [TL]) per stratum (A to E) and per species. (a) Fish size per stratum: fish size was significantly different among strata (Kruskal-Wallis rank sum test, df 3, p < 0.0001). (b) Fish size per species: fish size was significantly different among species (Kruskal-Wallis rank sum test, df $5 ; \mathrm{p}<0.0001$ ). Note that except O.den (recorded $\mathrm{TL}_{\max }=11 \mathrm{~cm}$ ), the known size ranges of all other species (metamorphosed stages) are well represented (Table S5 in the supplement). P.gra $=$ Periophthalmus gracilis; P.var $=$ P. variabilis; P.chr. = P. chrysospilos; B.bod = Boleophthalmus boddarti; B.pec $=B$. pectinirostris; O.den $=$ Oxuderces dentatus. Boxplots, middle line: mean; box: mean $\pm \mathrm{SD}_{\text {; }}$ whiskers: min-max values

Table 3. Post-hoc pairwise comparisons of fish size after significant overall size differences amongst strata and species were found ( $p$-values are reported: Mann-Whitney $U$-test with Holm's sequential Bonferroni corrections; see Fig. 3 for abbreviations). a: size comparisons between strata. b: size comparisons between species

\begin{tabular}{|lccrrrrrrr|r}
\hline $\mathbf{a}$ & A & B & C & D & b & P.gra & P.var & P.chr & B.bod & B.pec \\
\hline A & & & & & P.gra & & & \\
B & 0.887 & & & & P.var & $<0.001$ & & \\
C & 0.540 & 0.319 & & & P.chr & 0.061 & 0.049 & & \\
D & 0.027 & 0.082 & 0.290 & & B.bod & $<0.001$ & 0.002 & $<0.001$ & \\
E & 0.001 & $<0.001$ & $<0.001$ & 0.008 & B.pec & $<0.001$ & $<0.001$ & $<0.001$ & 0.805 & \\
& & & & & O.den & 0.046 & 0.055 & 0.425 & $<0.001$ & $<0.001$ \\
\hline
\end{tabular}




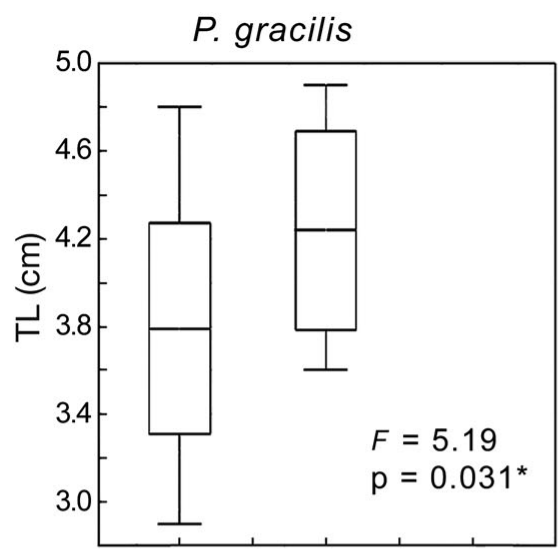

B. boddarti

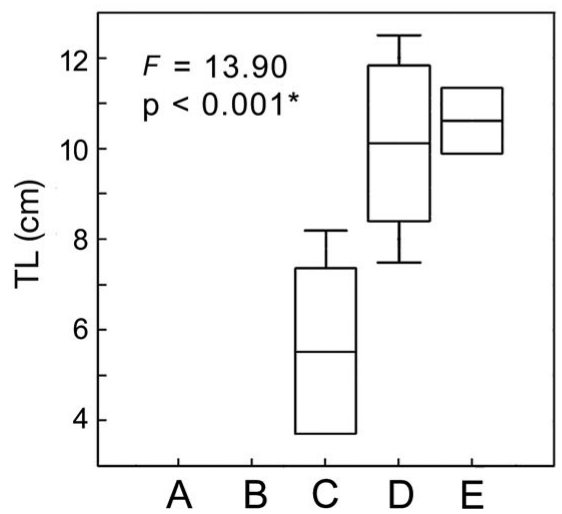

P. variabilis

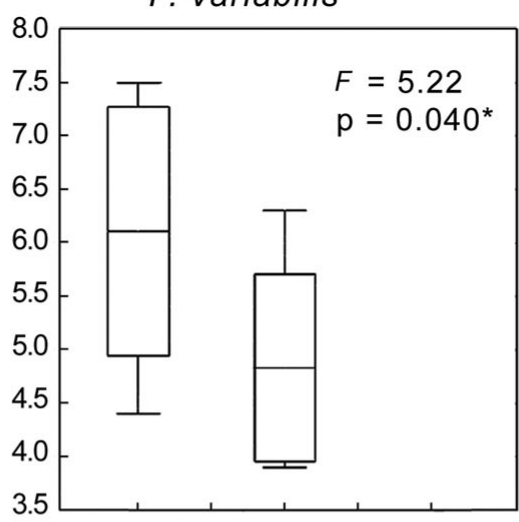

B. pectinirostris

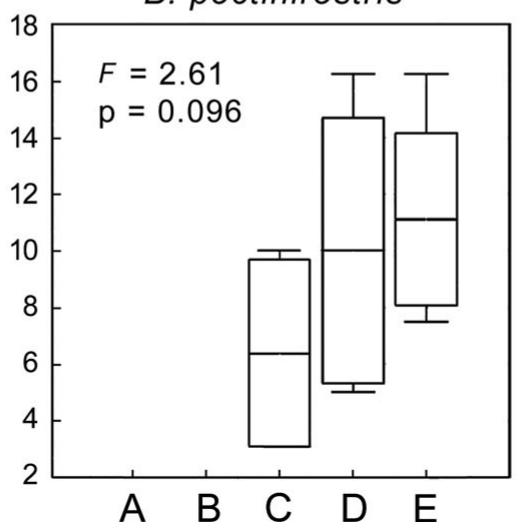

P. chrysospilos

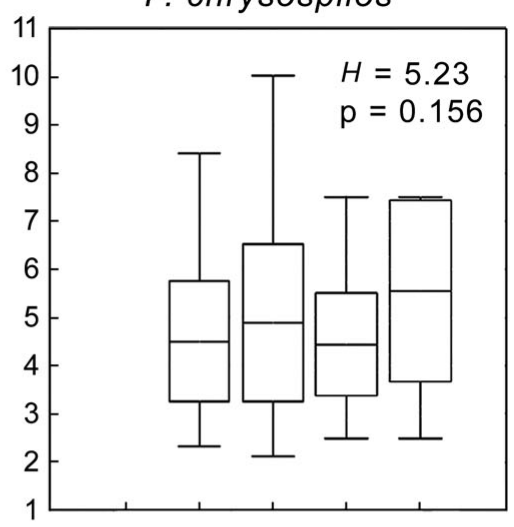

O. dentatus

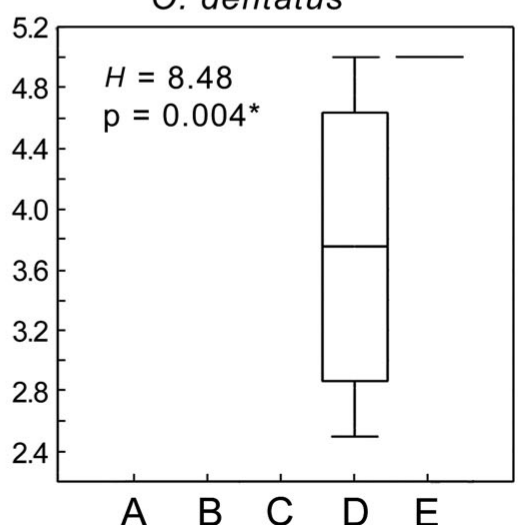

Fig. 4. Boxplots of total length (TL) by stratum for each species. Periophthalmus variabilis significantly increased in size towards land; P. chrysospilos and Boleophthalmus pectinirostris did not show significant size differences among strata; all other species significantly decreased in size towards land (one-way ANOVA or Kruskal-Wallis rank sum test: $F$ or $H$, respectively, and p-values are reported). In particular, size of $B$. boddarti in Strata D and E was significantly larger than in Stratum C (post-hoc Tukey's honestly significant difference test, $\mathrm{p}<0.01$ ). Midpoints between means within strata were used to define different size classes in those species with significant differences in size between strata (see 'Results'). Boxplots and other abbreviations as in Fig. 3. ${ }^{*}$ significant TL differences $(\mathrm{p}<0.05)$ between different strata

(midpoint $=5.5 \mathrm{~cm}, \mathrm{TL}$ in Stratum A $>$ TL in Stratum C), Boleophthalmus boddarti (midpoint $=8.0 \mathrm{~cm}$, TL in Strata D and E > TL in Stratum C) and Oxuderces dentatus (midpoint $=4.4 \mathrm{~cm}$, TL in Stratum E $>\mathrm{TL}$ in Stratum D). Boleophthalmus pectinirostris apparently varied in size among strata, but not significantly so (Fig. 4). All the species increased in size towards the sea, except $P$. variabilis, which decreased in size, and Periophthalmus chrysospilos, which exhibited an unclear pattern (Figs. 4 \& 5).

Three groups of strata with respect to the measured environmental parameters were defined by the cluster analysis: A, B + C, and D + E (Gower index, similarity cutoff value $=0.6$; Fig. S6 in the supplement).

MCA showed 2 different associations of species and size classes with different quantities of environmental water (Fig. 6a, Tables S2 \& S3). The first 2 factorial axes (F1, F2) accounted for $84.9 \%$ of total variance; all species and size classes were significantly associated with ordinal environmental parameters in the factorial space (level alpha $=0.05$ ). These results were consistent with AHC (Fig. 6b: cutoff similarity value 0.70).

Group P included Periophthalmus gracilis and P. variabilis (AHC node similarity: 0.91). This group was associated with forested areas (VC2, VC3), heterogeneous substrates (SE3, SE4), smaller water bodies (WB2, WB3), and variable tidal conditions (TI2 to TI4). These species were prevalently found inside Stratum $\mathrm{A}_{\text {; }}$ nonetheless, their occurrence here was mainly restricted to the area towards the bund channel (Figs. 2 \& 5).

Group Q included all the other species and size classes (AHC node similarity: 0.73). All these species were associated with absence of vegetation coverage (VC1), homogeneous substrates (SE1), larger water bodies (WB1), and higher tidal influence (TI1, TI2). Periophthalmus chrysospilos and smaller Boleophthalmus boddarti were found in more terrestrial conditions 


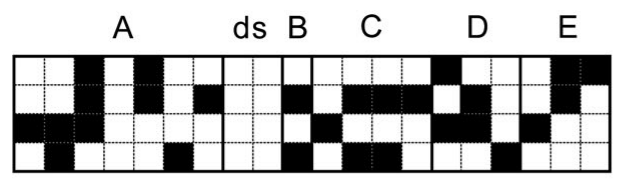

P. gracilis $(\mathrm{TL}>4.0 \mathrm{~cm})$

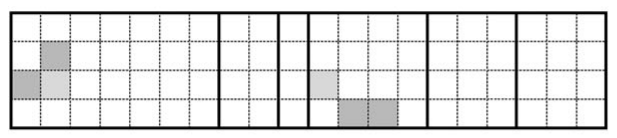

P. variabilis $(\mathrm{TL}>5.5 \mathrm{~cm})$

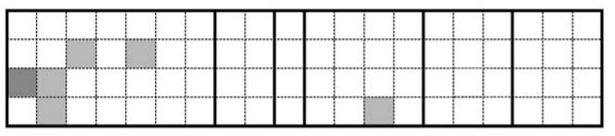

P. chrysospilos

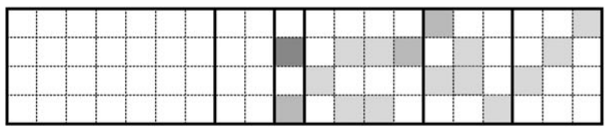

B. boddarti $(\mathrm{TL} \leq 8.0 \mathrm{~cm})$

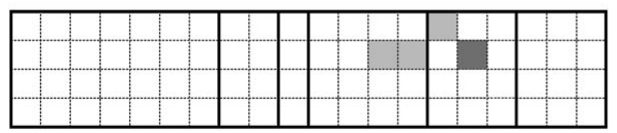

O. dentatus $(\mathrm{TL}>4.4 \mathrm{~cm})$

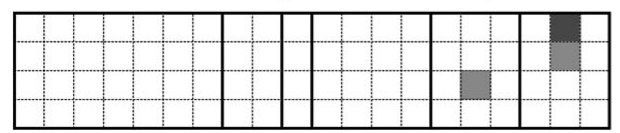

P. gracilis $(\mathrm{TL} \leq 4.0 \mathrm{~cm})$

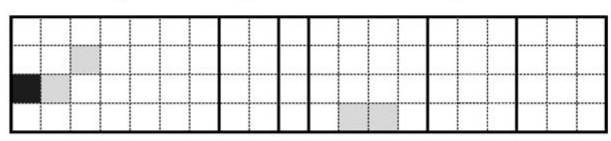

P. variabilis $(\mathrm{TL} \leq 5.5 \mathrm{~cm})$

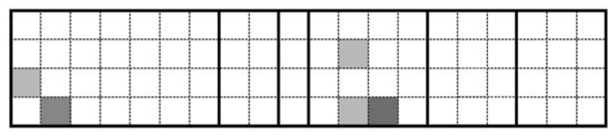

B. boddarti $(\mathrm{TL}>8.0 \mathrm{~cm})$

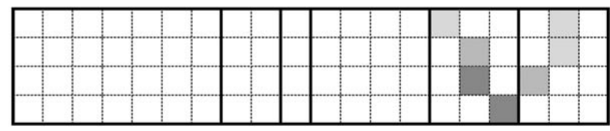

B. pectinirostris

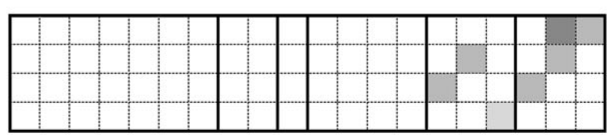

O. dentatus $(\mathrm{TL} \leq 4.4 \mathrm{~cm})$

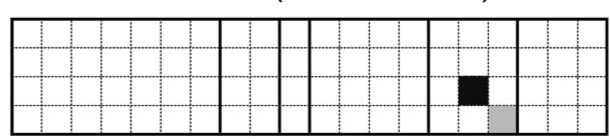

0.00

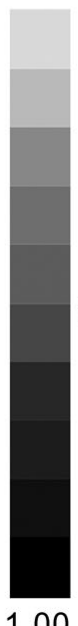

Rel. abun.

Fig. 5. Overall distribution and abundance of the studied species and size classes in the sampling grid (see Fig. 4). For better clarity, in diagrams each cell (representing $12 \times 12 \mathrm{~m}$ ) is centred on a node of the real grid; the sea is on the right (see Fig. 2). In the left upper corner, the randomized sampled nodes (blackened cells indicate where quadrats were positioned) and the strata (A to

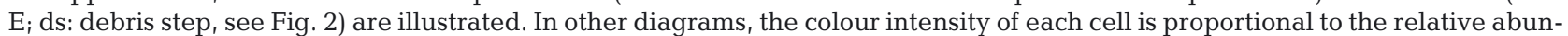
dance (Rel. abun.) of the species and size class measured in the respective quadrat. P.: Periophthalmus; B.: Boleophthalmus; O.: Oxuderces. TL: total length

(VC2; SE2, SE3). P. chrysospilos was also found in areas flooded at least by the mean high water spring (TI3), and smaller $B$. boddarti were never found in areas with the highest tidal influence (TI1).

The relative position in the LV, WA space of $80 \%$ concentration ellipses containing individuals of the same species and size class (Fig. 6c), showed that Oxuderces dentatus and Boleophthalmus pectinirostris were found in the most aquatic conditions (higher LV and lower WA), while Periophthalmus gracilis and $P$. variabilis were found in the most terrestrial conditions (lower LV and higher WA). P. chrysospilos and Boleophthalmus boddarti were in an intermediate position. Within species, larger Oxuderces dentatus and $B$. boddarti were found in more aquatic conditions than smaller individuals, even if large overlaps were present. No differences were observed between different size classes of $P$. variabilis and $P$. gracilis.

The cluster analysis of species and size classes against their distribution among strata only partially recovered the associations found with ordinal and continuous environmental parameters (Fig. 6d; cutoff similarity value $=0.70$ ). Among the species included in Group P (Fig. 6a,b), AHC and MCA found a difference only between the size classes of Periophthalmus gracilis; on the contrary, size classes of both $P$. gracilis and $P$. variabilis were never sister groups in the dendrogram (Fig. 6d). Among the species included in Group Q (Fig. 6a,b), the dendrogram described smaller and larger Boleophthalmus boddarti as even more distantly related than in $\mathrm{AHC}$ and $\mathrm{MCA}_{\text {; }}$ smaller and larger Oxuderces dentatus were also positioned in dif- 

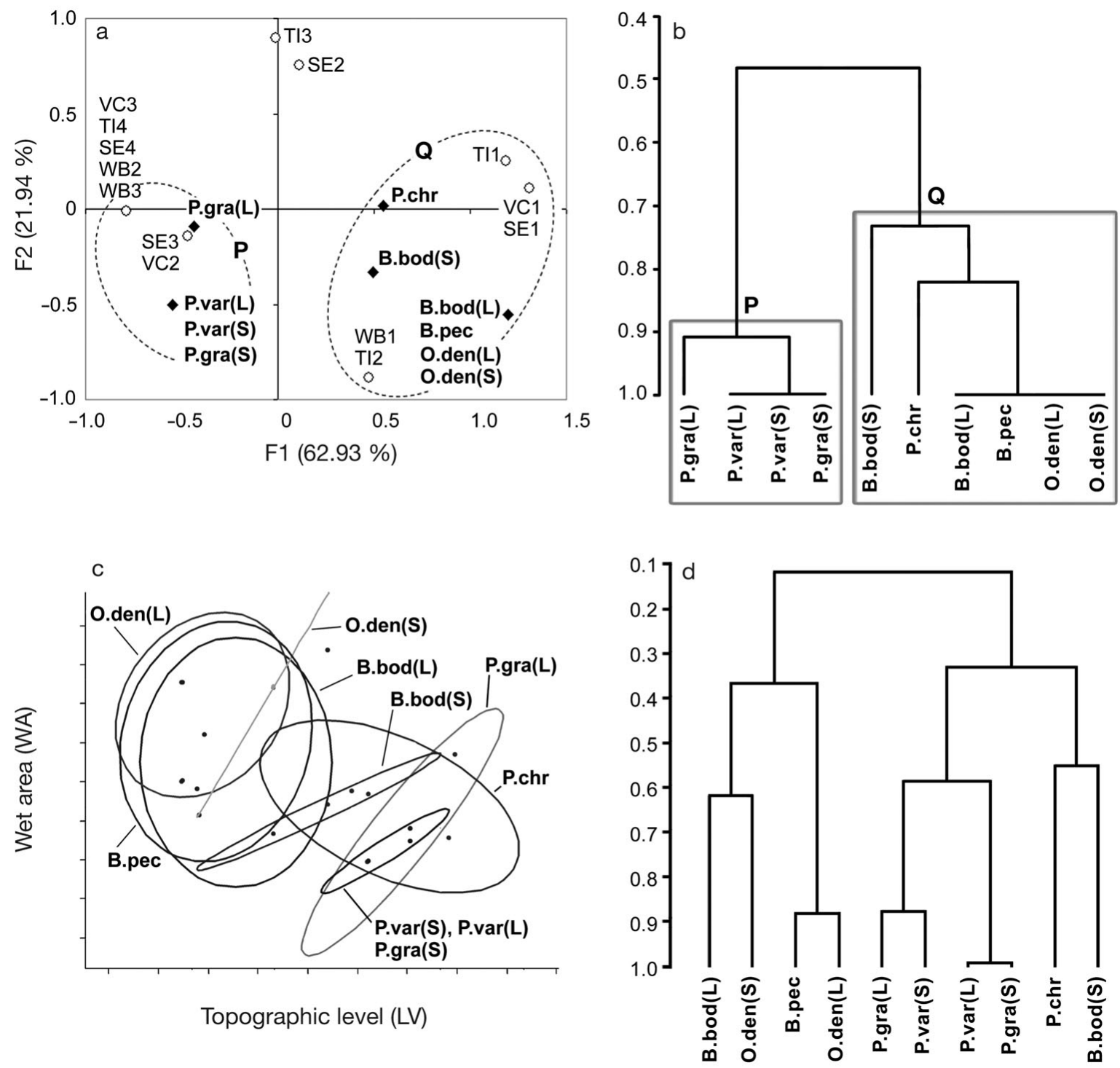

Fig. 6. Associations of species and size classes defined by environmental conditions and spatial distribution. (a) Multiple correspondence analysis (MCA) of species and size classes (modalities; black diamonds) and ordinal parameters (observations: VC [density of vegetation coverage], WB [water bodies], TI [tidal influence], and SE [structural elements]; open circles); the factorial axes F1 and F2 explain the highest percentage of variance (in parentheses); arbitrary dashed ellipses delineate species and size class associations $(\mathrm{P}, \mathrm{Q})$ which correspond to clusters from agglomerative hierarchical clustering (AHC). (b) AHC of species and size classes (gray boxes delineate the utilised clusters: cutoff value $=0.7$ ). Both MCA and AHC supported 2 associations: $P$ in more terrestrial conditions, and $Q$ in more aquatic conditions. (c) Occurrences of species and size classes plotted in the WA (relative wet area), LV (topographic level) space (normalised data; LV was not available for Stratum A); $80 \%$ concentration ellipses illustrate how different species and size classes occurred in different conditions, from more aquatic (higher WA, lower LV) to more terrestrial (lower WA, higher LV). This pattern is compatible with the outcome of MCA and AHC. (d) Cluster analysis of species and size class distribution among strata described spatially segregated associations among strata (UPGMA, Bray-Curtis index; see also Fig. 5), which only partially corresponded with the associations defined by environmental parameters. Within species, different size classes were never sister groups, i.e. different intraspecific life stages were apparently spatially partitioned.

L: large, S: small; see Fig. 5 for size classes and Fig. 3 for other abbreviations

ferent clusters, although they were found in similar environmental conditions.

Our results (Fig. 6) showed that species were both spatially partitioned amongst strata and reflected habitat checkerboards relative to environmental conditions. Therefore, to investigate whether synecological interactions also influenced distribution, we measured co-occurrence only within the guilds based on environmental conditions (Fig. 6a: P, Q). This analysis suggested that the community was not shaped by competition at the observed spatial scale, since no significant negative co-occurrence was found. Indeed, in both 
associations, C-scores were significantly lower than chance (Group P: $p=0.00$; Group Q: $p=0.03$ ), indicating significant and positive co-occurrence. The numbers of perfect checkerboards and of combinations were never statistically significant.

\section{DISCUSSION}

All the recorded species were consistent with the available taxonomic keys and field identification notes of previous studies in this region (Murdy 1989, Takita et al. 1999, Khaironizam \& Norma-Rashid 2005, Jaafar et al. 2006, Jaafar \& Larson 2008, Jaafar et al. 2009, Polgar \& Crosa 2009).

The steep deposit of wood and garbage in front of the erosive step (debris step, Fig. 2) prevented the tide to flood the high forest from the sea, explaining the absence of ephemeral tidal inlets inside Stratum A. The forest floor was only flooded by rain, extreme high tides, or high tides which overflowed the reclamation bund channel when the closure of the sluice gate was delayed (G. Polgar, pers. obs.). The drier conditions of Stratum A, related to the presence of heterogeneous deposits in front of the erosive step (debris step) during this study, probably determined the lower goby densities observed in this area (Table S4 in the supplement); the bund channel may have also determined heterogeneous environmental conditions in this stratum, inducing higher densities near the water (Fig. 5). On the other hand, much of the coarser vegetal debris (large logs, garbage, flotsam) had disappeared from the erosive step after 1 yr (November 2007: G. Polgar, pers. obs.), demonstrating extremely dynamic conditions, possibly on a seasonal basis (monsoons). The presence of consistent temporal variability of hydrological patterns could be an important aspect of the dynamics of mangrove resident animals and is probably worthy of further investigation. To our knowledge, no such studies are presently available.

The narrow unvegetated area in front of the erosive step (Stratum B) had different sedimentary characteristics relative to other strata, with coarser fractions of fibrous peat and fine sand, possibly due to wave action during high tide (Fig. 2). For the rest, general environmental conditions resembled those found in other similar habitats (Takita et al. 1999, Polgar 2008, Polgar \& Crosa 2009).

The distribution patterns and multivariate correspondence to environmental variables that we found were consistent with previous descriptive and semiquantitative studies (Polgar \& Crosa 2009, and references therein). In particular, this study confirmed the ecological guilds found by Polgar \& Crosa (2009) in other Malayan communities, with only Periophthalmus spp. in the more terrestrial guild, and Boleophthalmus spp. and $P$. chrysospilos in the most aquatic one.

The differential association of oxudercine species with different environmental conditions was mirrored by a differential spatial distribution along the intertidal zone during low tide. ANOVA showed a variation of size amongst both strata and species, with an increase in size from land to sea. That is, larger species (i.e. Boleophthalmus spp.) were found in lower strata along the vertical intertidal gradient. Differences in maximum size were even more evident and showed the same pattern (Fig. 3, Table 3 \& Table S5 in the supplement).

The pattern observed at the intraspecific level was more composite. Smaller classes were found in more terrestrial strata in Periophthalmus gracilis, Boleophthalmus boddarti, and Oxuderces dentatus; the same pattern was observed in Boleophthalmus pectinirostris, although it was not statistically significant. Periophthalmus chrysospilos did not show distinct patterns, and Periophthalmus variabilis actually increased in size towards land.

The cluster analysis of strata against environmental parameters was consistent with the hypothesis of a stratification with respect to the quantity of environmental water. Exploratory analyses confirmed the association between different species and both ordinal (VC, WB, SE, TI) and continuous measures of the quantity of environmental water (LV, WA). In this latter case, different size classes of Boleophthalmus boddarti and Oxuderces dentatus were also differentiated, with larger classes found in more aquatic conditions. Our results were partially consistent with those of Muhammad Ali \& Norma-Rashid (2005), who found an ecological partition between different size classes of B. boddarti, with smaller individuals found only along riverbanks inside forests, and Periophthalmus gracilis only in forested areas. Contrary to our findings, these authors found that larger Periophthalmus chrysospilos were more abundant on mudflats, while smaller and intermediate classes prevailed in forested areas, both on the forest floor and along riverbanks, consistent with a decrease in size from more aquatic to more terrestrial habitats. These differences may reflect the different types of mangrove systems studied (fringe mangrove versus riverine mangrove forests).

At the synecological level, the spatial segregation between different size classes among strata suggested by the cluster analysis was not confirmed by the cooccurrence analysis. Within guilds associated with homogeneous environmental conditions, the community was apparently not structured by negative interactions (predation, interference competition), but by positive or neutral interactions. This suggests that at the scale considered and within guilds, the selection of similar and not homogeneously distributed resources 
(e.g. prey, environmental conditions) and the presence of shared predators or parasites were more important structuring factors. These results apparently contrasted with those obtained by Polgar \& Crosa (2009); nonetheless, the large oxudercine predator Periophthalmodon schlosseri, which in the latter study was in negative co-occurrence with smaller Periophthalmus spp., was excluded from the present analyses.

Within the monophyletic Periophthalmini (Murdy 1989), the studied species of Periophthalmus, morphologically more derived and better adapted to an amphibious lifestyle (Murdy 1989), were smaller than Boleophthalmus spp., suggesting a negative relationship between size and terrestriality. P. chrysospilos, which was found in more aquatic conditions than the other studied congeners, also attains a larger maximum size than the latter species (Tables 3b \& S5). In this respect, the genus Periophthalmodon, sister to Periophthalmus in Murdy's cladogram (1989), includes 2 of the largest oxudercine species: Periophthalmodon schlosseri and Periophthalmodon freycineti. Nonetheless, even if these large species can be found in forested habitats, they are prevalently found near the water's edge (Nursall 1981, Takita et al. 1999, Polgar \& Crosa 2009) and are probably less adapted to an amphibious lifestyle than the smaller congener Periophthalmodon septemradiatus (Khaironizam \& NormaRashid 2003) and Periophthalmus spp.

At the interspecific level, the ecomorphological pattern observed supports the hypothesis of a selective advantage of smaller size in more terrestrial habitats. Such advantage could be mediated by ecophysiological or behavioural effects related to a smaller size, such as higher diffusion rates through epithelia (Evans et al. 1999), smaller gravity and drag forces during amphibious locomotion, easier selection of appropriate microhabitat conditions; or better manoeuvrability and easier burrowing activities on more heterogeneous substrates. In this case, the passage to more terrestrial conditions could have been facilitated by miniaturisation, a widespread evolutionary trend in gobioids (e.g. Iwata et al. 2001, Kon \& Yoshino 2002, Watson \& Walker 2004). Nonetheless, such interpretation was only partly supported by our analyses at the intraspecific level. In particular, the occurrence of larger individuals at lower levels (e.g. in both Boleophthalmus spp.) could also be explained by the presence of a more intense predatory pressure during both high and low tide (Polgar \& Crosa 2009), suggesting that smaller individuals use higher and spatially more heterogeneous environments to take shelter from predators. Other explanations could be habitat selection mediated by different trophic niches. The presence of the herbivorous Boleophthalmus spp. at lower topographical levels could be related to the higher abundance of benthic diatoms on unvegetated and more illuminated substrates (Polgar \& Crosa 2009). Some oxudercine species could have also increased their adaptability to terrestrial conditions through co-evolution with other species, such as ecosystem engineers (i.e. burrowing benthic invertebrates, or plants with different root structures), which can drastically modify microhabitat conditions. Finally, all the proposed mechanisms are not mutually exclusive and may act in synergism.

Interestingly, paedomorphic trends were observed in some evolutionary lineages of Late Devonian tetrapodomorphs and of the first semi-aquatic vertebrates (Long 1990, Long \& Gordon 2004). Subsequently, during the explosive Tournasian (early Carboniferous) radiation of amphibious tetrapods, many dwarfed and diverse forms gradually colonised semi-terrestrial habitats. Also in this case, miniaturisation apparently facilitated the development of structural and functional adaptations to semi-terrestrial conditions (Clack 2002).

In fact, oxudercine gobies were proposed as convergent eco-evolutionary models of the Devonian transition (e.g. Schultze 1999). This intriguing analogy suggests the presence of convergent ecological and evolutionary trends both in these ancient forms and mudskippers, which independently radiated into semiaquatic and semi-terrestrial habitats in surprisingly similar ecological conditions (intertidal flats and alluvial plains), as shown by recent paleoecological evidences (Clack 2006, 2007, Niedêwiedzki et al. 2010). As in mudskippers, the eco-evolutionary transition from water to land could have been facilitated by lower competition levels and unexploited trophic resources in more terrestrial conditions (Clack 2002, Polgar \& Crosa 2009).

This study is the first attempt to quantify and evaluate statistically the abundance and distribution of oxudercine gobies along the intertidal zone. More surveys are needed from different areas and regions, and more efficient sampling methods. Comparative ecological perspectives would help us to understand the ecoevolutionary mechanisms that elicited and maintained the exploitation of semi-terrestrial habitats in oxudercine gobies, possibly revealing more general ecological and evolutionary processes along the water's edge.

Acknowledgements. This study is part of the project 'Ecology and evolution in different groups of animal species living in mangrove and adjacent ecosystems of Peninsular Malaysia', conducted in the States of Perak and Johor, Malaysia, in 2006. The first author thanks Puan Munirah (EPU, Putra Jaya, Malaysia), for her assistance and guidance during the application to conduct research in Malaysia. Many thanks also go to Prof. J. Pignatti (Dept. of Earth Sc., University of Rome 'La Sapienza', Italy); Dr. A. Sasekumar, Prof. V. C. Chong and his research staff: Ms. L. L. Chew, Ms. A. L. Ooi, Mr. H. H. Moh, and Ms. A. Then (Institute for Postgraduate Studies, University of Malaya, Kuala Lumpur, Malaysia). Thanks also go to 
Dr. N. H. Mohd Ghazali (Dept. of Irrigation and Drainage, Ministry of Natural Resource \& Environment, Kuala Lumpur, Malaysia). The first author also thanks the Johor park managers Mr. Harban Singh and Mrs. Lili Tokiman (Tanjung Piai and Kukup Taman Negara, Johor National Parks Corporation, Johor, Malaysia), and the parks' staffs. A PhD grant in Ecological Sciences (Dept. of Plant Biology, University of Rome 'La Sapienza', Italy) partially funded this survey.

\section{LITERATURE CITED}

Clack JA (2002) Gaining ground: the origin and evolution of tetrapods. Indiana University Press, Bloomington, IN

Clack JA (2006) The emergence of early tetrapods. Palaeogeogr Palaeoclimatol Palaeoecol 232:167-189

Clack JA (2007) Devonian climate change, breathing, and the origin of the tetrapod stem group. Integr Comp Biol 47: 510-523

Clayton DA (1993) Mudskippers. Oceanogr Mar Biol Annu Rev 31:507-577

Coleman JM, Gagliano SM, Smith WG (1970) Sedimentation in a Malaysian high tide tropical delta. In: Morgan JP (ed) Deltaic sedimentation, modern and ancient. S.E.P.M. Spec Publ No. 15, Society of Economic Paleontologists and Mineralogists, Tulsa, OK, p 185-197

Colombini I, Berti R, Ercolini A, Nocita A, Chelazzi L (1995) Environmental factors influencing the zonation and activity patterns of a population of Periophthalmus sobrinus Eggert in a Kenyan mangrove. J Exp Mar Biol Ecol 190: 135-149

Darumas U, Tantichodok P (2002) A new species of mudskipper (Gobiidae: Oxudercinae) from southern Thailand. Phuket Mar Biol Cent Res Bull 64:101-107

Dyer KR, Christie MC, Wright EW (2000) The classification of intertidal mudflats. Cont Shelf Res 20:1039-1060

English S, Wilkinson C, Baker V (eds) (1997) Survey manual for tropical marine resources, 2nd edn. Australian Institute of Marine Science, Townsville

Evans DH, Claiborne JB, Kormanik GA (1999) Osmoregulation, acid-base regulation and nitrogen excretion. In: Horn MH, Martin KLM, Chotkowski MA (eds) Intertidal fishes: life in two worlds. Academic Press, San Diego, p 79-96

Freeman MC, Stouder DJ (1989) Intraspecific interactions influence size depth distribution in Cottus bairdi. Environ Biol Fishes 24:231-236

Gibson RN (1982) Recent studies on the biology of intertidal fishes. Oceanogr Mar Biol Annu Rev 20:363-414

Gibson RN (1999) Methods for studying intertidal fishes. In: Horn MH, Martin KLM, Chotkowski MA (eds) Intertidal fishes: life in two worlds. Academic Press, San Diego, p 7-25

Gillanders BM, Able KW, Brown JA, Eggleston DB, Sheridan PF (2003) Evidence of connectivity between juvenile and adult habitats for mobile marine fauna: an important component of nurseries. Mar Ecol Prog Ser 247:281-295

Gotelli NJ, Ellison AM (2004) A primer of ecological statistics. Sinauer Associates, Sunderland, MA

Gotelli NJ, Entsminger GL (2002) EcoSim: Null models software for ecology. Version 7. Acquired Intelligence Inc \& Kesey-Bear, Jericho, VT; available at http:// garyentsminger.com/ecosim/index.htm

Haahr M (2006) Random.org: True random number service (Sequence generator). Web resource, available at www. random.org. Accessed Oct-Nov 2006

Hammer Ø, Harper DAT (2005) Palaeontological data analysis. Blackwell Publishing, Oxford
Hammer Ø, Harper DAT, Ryan PD (2001) PAST: Paleontological statistics software package for education and data analysis. Palaeontologia Electronica 4:9. Available at http://palaeo-electronica.org/2001_1/past/issue1_01.htm

- Harvey BC, Steward AJ (1991) Fish size and habitat depth relationships in headwater streams. Oecologia 87:336-342

> Hernández CE, Neill PE, Pulgar JM, Ojeda FP, Bozinovic F (2002) Water temperature fluctuations and territoriality in the intertidal zone: two possible explanations for the elevational distribution of body size in Graus nigra. J Fish Biol 61:472-488

Hoese DF (1984) Gobioidei: relationships. In: Moser HG, Richards WJ, Cohen DM, Fahay MP, Kendall AW Jr, Richardson SL (eds) Ontogeny and systematics of fishes. Spec Publ No. 1, American Society of Ichthyologists and Herpetologists, Allen Press, Lawrence, KS, p 588-591

Holme NA, McIntyre AD (1971) Methods for the study of marine benthos. IBP Handbook No 16. Blackwell Scientific Publications, Oxford

Horn MH (1999) Convergent evolution and community convergence: research potential using intertidal fishes. In: Horn MH, Martin KLM, Chotkowski MA (eds) Intertidal fishes: life in two worlds. Academic Press, San Diego, p 356-372

> Horn MH, Riegle C (1981) Evaporative water loss and intertidal vertical distribution in relation to body size and morphology of stichaeoid fishes from California. J Exp Mar Biol Ecol 50:273-288

> Ikebe Y, Oishi T (1997) Relationships between environmental factors and diel and annual changes of the behaviors during low tides in Periophthalmus modestus. Zool Sci 14: $49-55$

Iwata A, Hosoya S, Larson HK (2001) Paedogobius kimurai, a new genus and species of goby (Teleostei: Gobioidei: Gobiidae) from the west Pacific. Rec Aust Mus 53: 103-112

Jaafar Z, Larson HK (2008) A new species of mudskipper, Periophthalmus takita (Teleostei: Gobiidae: Oxudercinae), from Australia, with a key to the genus. Zool Sci 25: 946-952

Jaafar Z, Lim KKP, Chou LM (2006) Taxonomical and morphological notes on two species of mudskippers, Periophthalmus walailakae and Periophthalmodon schlosseri (Teleostei: Gobiidae) from Singapore. Zool Sci 23:1043-1047

Jaafar Z, Perrig M, Chou LM (2009) Periophthalmus variabilis (Teleostei: Gobiidae: Oxudercinae), a valid species of mudskipper, and a re-diagnosis of Periophthalmus novemradiatus. Zool Sci 26:309-314

Jobson JD (1992) Applied multivariate data analysis, Vol. II. Categorical and multivariate methods. Springer-Verlag, New York

Johnson RA, Wichern DW (1992) Applied multivariate statistical analysis. Prentice-Hall, Englewood Cliffs, NJ

Khaironizam MZ, Norma-Rashid Y (2003) First record of the mudskipper, Periophthalmodon septemradiatus (Hamilton) (Teleostei: Gobiidae) from Peninsular Malaysia. Raffles Bull Zool 51:97-100

Khaironizam MZ, Norma-Rashid Y (2005) Distribution of mudskippers (Gobiidae: Oxudercinae) on the Selangor coast. In: Sasekumar A, Chong VC (eds) Ecology of Klang Strait. Faculty of Science, University of Malaya, Kuala Lumpur, Malaysia, p 101-114

Kon T, Yoshino T (2002) Diversity and evolution of life histories of gobioid fishes from the viewpoint of heterochrony. Mar Freshw Res 53:377-402

Lessios HA (1996) Methods for quantifying abundance of marine organisms. In: Lang MA, Baldwin CC (eds) Meth- 
ods and techniques of underwater research. Proceedings of the American Academy of Underwater Sciences 16th Annual Scientific Diving Symposium, Smithsonian Institution, Washington DC. American Academy of Underwater Sciences, Nahant, MA, p 149-157

Long JA (1990) Heterochrony and the origin of tetrapods. Lethaia 23:157-166

Long JA, Gordon MS (2004) The greatest step in vertebrate history: a paleobiological review of the fish-tetrapod transition. Physiol Biochem Zool 77:700-719

Mazda Y, Magi M, Kogo M, Hong PN (1997) Mangroves as a coastal protection from waves in the Tong King delta, Vietnam. Mangroves Salt Marshes 1:127-135

Milward NE (1974) Studies on the taxonomy, ecology and physiology of Queensland mudskippers. PhD thesis, University of Queensland, Brisbane

Muhammad Ali SH, Norma-Rashid Y (2005) Size class distribution and behaviour budgets of sympatric mudskippers utilising mangrove microhabitats in Morib. In: Sasekumar A, Chong VC (eds) Ecology of Klang Strait. Faculty of Science, University of Malaya, Kuala Lumpur, p 115-126

Murdy EO (1989) A taxonomic revision and cladistic analysis of the oxudercine gobies (Gobiidae: Oxudercinae). Rec Aust Mus Suppl No. 11:1-93

Murdy EO, Takita T (1999) Periophthalmus spilotus, a new species of mudskipper from Sumatra (Gobiidae: Oxudercinae). Ichthyol Res 46:367-370

Niedêwiedzki G, Szrek P, Narkeiwicz K, Narkeiwicz M, Ahlberg PE (2010) Tetrapod trackways from the early Middle Devonian period of Poland. Nature 463:43-48

Nursall JR (1981) Behaviour and habitat affecting the distribution of five species of sympatric mudskippers in Queensland. Bull Mar Sci 31:730-735

Polgar G (2009) Species-area relationship and potential role as a biomonitor of mangrove communities of Malayan mudskippers. Wetl Ecol Manag 17:157-164

Polgar G, Crosa G (2009) Multivariate characterisation of the habitats of seven species of Malayan mudskippers (Gobiidae: Oxudercinae). Mar Biol 156:1475-1486

Raffaelli D, Hawkins S (1999) Intertidal ecology. Kluwer Academic Publishers, Dordrecht

Ramakrishna S, Loganathan MT, Hua SC (2001) Ecological assessment of Sungai Pulai mangrove forest and proposed

Editorial responsibility: Jake Rice,

Ottawa, Canada
Tanjung Piai State Park, Johor to determine their status as wetlands of international importance (Ramsar Sites). Introduction: Analysis of threats \& management issues $(1.0$ - 3.2.6.4). For the Johor National Parks Corporation. Wetlands International, Petaling Jaya

Sarpedonti V, Sasekumar A (1996) The abundance of diatom species on a low shore mangrove forest, Sementa, Malaysia. Wallaceana 77:21-26

Sasekumar A (1974) Distribution of macrofauna on a Malayan mangrove shore. J Anim Ecol 43:51-69

Sasekumar A (1980) The present state of mangrove ecosystems in southeast Asia and the impact of pollutionMalaysia (SCS/ 80/WP/94b). FAO/UNEP project: Impact of pollution on the mangrove ecosystem and its productivity in Southeast Asia. Publication of the South China Sea Fisheries Development and Coordinating Programme, Manila

Sasekumar A (1994) Meiofauna on a mangrove shore on the west coast of Peninsular Malaysia. Raffles Bull Zool 42: 901-915

Sayer MDJ (2005) Adaptations of amphibious fish for surviving life out of water. Fish Fish 6:186-211

Schultze HP (1999). The fossil record of the intertidal zone. In: Horn MH, Martin KLM, Chotkowski MA (eds) Intertidal fishes: life in two worlds. Academic Press, San Diego, p 373-392

Spina AP (2000) Habitat partitioning in a patchy environment: considering the role of intraspecific competition. Environ Biol Fishes 57:393-400

Swennen C, Ruttanadakul N, Haver M, Piummongkol S and others (1995) The five sympatric mudskippers (Teleostei: Gobioidea) of Pattani area, Southern Thailand. Nat Hist Bull Siam Soc 42:109-129

Takita T, Agusnimar, Ali AB (1999) Distribution and habitat requirements of oxudercine gobies (Gobiidae: Oxudercinae) along the Straits of Malacca. Ichthyol Res 46:131-138

Watson W, Walker HJ Jr (2004) The world's smallest vertebrate, Schindleria brevipinguis, a new paedomorphic species in the family Schindleriidae (Perciformes: Gobioidei). Rec Aust Mus 56:139-142

Zander CD, Nieder J, Martin KLM (1999). Vertical distribution patterns. In: Horn MH, Martin KLM, Chotkowski MA (eds) Intertidal fishes: life in two worlds. Academic Press, San Diego, p 26-53

Submitted: January 11, 2010; Accepted: March 22, 2010

Proofs received from author(s): June 10, 2010 